\title{
Morphine-induced postconditioning modulates mitochondrial permeability transition pore opening via delta- 1 opioid receptors activation in isolated rat hearts
}

\author{
June Hong Kim ${ }^{1}$, Kook Jin Chun ${ }^{1}$, Yong Hyun Park ${ }^{1}$, Jun Kim ${ }^{1}$, Jeong Su Kim ${ }^{1}$, Young Ho Jang ${ }^{1,2}$, \\ Mi Young Lee ${ }^{3}$, and Jae Hong Park ${ }^{4}$ \\ ${ }^{1}$ Institute of Cardiovascular Research, Pusan National University Yangsan Hospital, Yangsan, ${ }^{2}$ Department of Anesthesiology, Pureun \\ Hospital, ${ }^{3}$ Department of Preventive Medicine, School of Medicine, Keimyoung University, Daegu, ${ }^{4}$ Department of Anesthesiology \\ and Pain Medicine, Haeundae Paik Hospital, Inje University, Busan, Korea
}

Background: It is generally accepted that morphine affords cardioprotection against ischemia/reperfusion injury. Inhibition of the mitochondrial permeability transition pore (MPTP) is considered an end target for cardioprotection. The aim of this study was to investigate the involvement of opioid receptors (OR) and MPTP in morphine-induced postconditioning (M-Post).

Methods: Isolated rat hearts were subjected to $30 \mathrm{~min}$ of regional ischemia and $2 \mathrm{~h}$ of reperfusion. Hearts were treated with $1 \mu \mathrm{M}$ morphine, with or without the OR antagonists or a MPTP opener at early reperfusion. Infarct size was measured with 2,3,5-triphenyltetrazolium chloride staining.

Results: There were no significant differences in cardiodynamic variables except a decrease in heart rate in the M-Post group ( $\mathrm{P}<0.01$ vs. control) after reperfusion. M-Post dramatically reduced infarct-risk volume ratio $(9.8 \pm$ $2.5 \%, \mathrm{P}<0.001$ vs. $30.0 \pm 3.7 \%$ in control). This beneficial effect on infarct volume by M-Post was comparable with ischemic postconditioning $(11.9 \pm 2.2 \%, \mathrm{P}>0.05)$. The nonspecific $\mathrm{OR}$ antagonist naloxone $(25.7 \pm 1.9 \%, \mathrm{P}<0.01)$, the $\delta$-OR antagonist naltrindole $(27.8 \pm 4.3 \%, \mathrm{P}<0.05)$ and $\delta_{1}$-OR antagonist 7 -benzylidenenaltrexone $(24.7 \pm 3.7 \%, \mathrm{P}$ $<0.01)$ totally abrogated the anti-infarct effect of M-Post. In addition, the anti-infarct effect by M-Post was also totally blocked by the MPTP opener atractyloside $(26.3 \pm 5.2 \%, \mathrm{P}<0.05)$.

Conclusions: M-Post effectively reduces myocardial infarction. The anti-infarct effect by M-Post is mediated via activation of $\delta$-OR, especially $\delta_{1}$-OR, and inhibition of the MPTP opening. (Korean J Anesthesiol 2011; 61: 69-74)

Key Words: Mitochondrial permeability transition pore, Morphine, Opioid receptors, Postconditioning, Reperfusion injury.

\footnotetext{
Received: October 20, 2010. Revised: January 20, 2011. Accepted: March 7, 2011.

Corresponding author: Young Ho Jang, M.D., Ph.D., Institute of Cardiovascular Research Center, Pusan National University Yangsan Hospital, Beoneo-ri, Mulgeum-eup, Yangsan 626-770, Korea. Tel: 82-55-360-1459, Fax: 82-55-360-2204, E-mail: weonjo@pnuyh.co.kr

(c) This is an open-access article distributed under the terms of the Creative Commons Attribution Non-Commercial License (http:// creativecommons.org/licenses/by-nc/3.0/), which permits unrestricted non-commercial use, distribution, and reproduction in any medium, provided the original work is properly cited.
} 


\section{Introduction}

Morphine is commonly used for chest pain in acute myocardial infarction. Morphine is a nonspecific opioid receptor (OR) agonist, meaning it activates all of the OR subtypes, i.e. $\mu-, \delta$ - and $\kappa$-OR subtypes. It has been proposed that morphineinduced preconditioning (M-Pre) confers cardioprotection against ischemia/reperfusion (I/R) injury and this effect is as effective as ischemic preconditioning (I-Pre) [1]. The cardioprotective effect by M-Pre involves the activation of $\delta$-OR, especially $\delta_{1}$-OR $[2,3]$. Recently, it has been demonstrated that morphine-induced postconditioning (M-Post) is also cardioprotective in I/R-injured hearts [4]. Therefore, it is highly possible that M-Post may involve $\delta$-OR.

Meanwhile, the mitochondrial permeability transition pore (MPTP) opening is considered an end target for the cardioprotection against I/R injury $[5,6]$. It has been generally accepted that the inhibition of the MPTP opening is a crucial event for cardioprotection in both I-Pre [7] and ischemic postconditioning (I-Post) [8]. Recently, it was reported that morphine prevents the MPTP opening in rat cardiomyocytes [9]. In the present study, we investigated the involvement of the $\delta$-OR subtype and MPTP in M-Post in isolated rat hearts.

\section{Materials and Methods}

The experimental procedures and protocols used in this study were reviewed and approved by the Institutional Animal Care and Use committee of our hospital. Male Sprague-Dawley rats (270-320 g) were obtained from KOATECH Co, Cheongwongun, Republic of Korea. Rats were anesthetized with $100 \mathrm{mg} /$ kg of pentobarbital sodium (Entobar ${ }^{\circledR}$, Hanlim Pharmacy, Yongin, Korea), and then anticoagulated with 300 IU of heparin administered intraperitoneally. Coronary perfusion using the Langendorff system with modified Krebs-Henseleit
(KH) solution, containing $118.5 \mathrm{NaCl}, 4.7 \mathrm{KCl}, 1.2 \mathrm{MgSO}_{4}, 1.8$ $\mathrm{CaCl}_{2}, 24.8 \mathrm{NaHCO}_{3}, 1.2 \mathrm{KH}_{2} \mathrm{PO}_{4}$, and 10 glucose (in mM) was performed as described previously [10]. All hearts were allowed to stabilize for at least $20 \mathrm{~min}$ before induction of ischemia. Hearts were subjected to $30 \mathrm{~min}$ of regional ischemia and $2 \mathrm{~h}$ of reperfusion. To induce regional ischemia, a snare was made at the level of the proximal length of left coronary artery. Regional ischemia was induced by pulling the snare and confirmed by regional cyanosis in addition to a substantial decrease in left ventricular developed pressure (LVDP). Reperfusion was started by releasing the snare. Hearts experiencing ventricular fibrillation (VF) after reperfusion usually revert spontaneously to a sinus rhythm. VF lasting more than $30 \mathrm{~s}$ was treated with a finger flick cardioversion until a perfusing rhythm was obtained. No pharmacological agents were used for defibrillation. In isolated hearts, a KH buffer-filled latex balloon was inserted into the left ventricle (LV) and was adjusted to 5-10 $\mathrm{mmHg}$ of left ventricular end-diastolic pressure (LVEDP) at the beginning of the experiment. Cardiodynamic variables, including heart rate (HR), left ventricular systolic pressure (LVSP) and LVEDP were recorded with the BIOPAC system (BIOPAC Systems Inc., CA, USA). LVDP and rate-pressure product (RPP) were calculated as follows; LVDP $=$ LVSP - LVEDP and RPP $=$ LVDP $\times$ HR. Maximum of the first derivative of $\mathrm{LV}\left(+\mathrm{dP} / \mathrm{dt}_{\max }\right)$ was analyzed using an analysis software (BSL v3.7.3.). Coronary flow (CF) was measured by collecting perfusate dripping from the right heart into a graduated cylinder.

Isolated rat hearts were randomly allocated to control (CON, no other intervention either before or after index ischemia) and treated groups (Fig. 1). In the M-Post group, morphine was added to the perfusate $5 \mathrm{~min}$ prior to reperfusion to $30 \mathrm{~min}$ after reperfusion at a concentration of $1 \mu \mathrm{M}$. As a comparison, another group of hearts was induced with I-Post by 6 cycles each of $10 \mathrm{~s}$ reperfusion and $10 \mathrm{~s}$ global ischemia. To assess the involvement of $\delta$-OR in M-Post, $100 \mu \mathrm{M}$ of the non-selective

\begin{tabular}{lcc} 
Stabilization & $\begin{array}{c}\text { Ischemia } \\
(30 \mathrm{~min})\end{array}$ & $\begin{array}{c}\text { Reperfusion } \\
(2 \mathrm{~h})\end{array}$ \\
Control & & \\
\hline
\end{tabular}

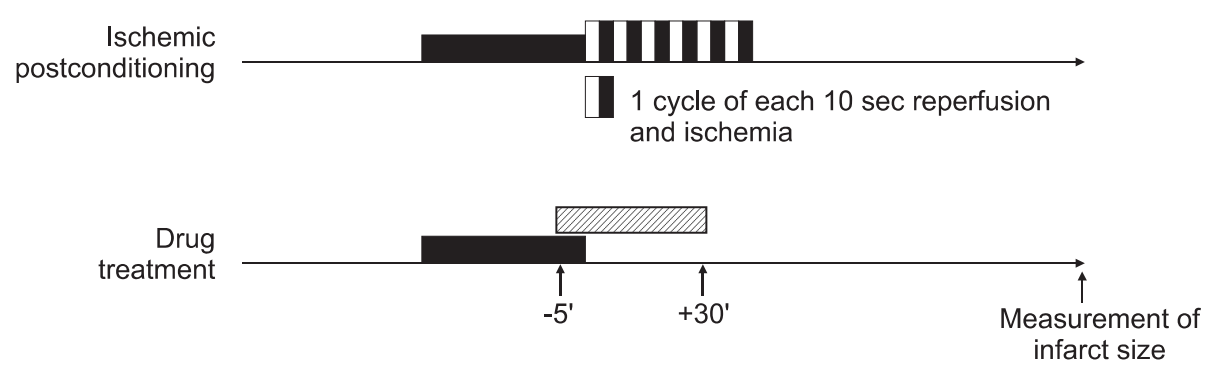

Fig. 1. Experimental protocols. For measurement of contractile function and infarct size, isolated rat hearts are exposed to $30 \mathrm{~min}$ ischemia followed by $2 \mathrm{~h}$ reperfusion. Ischemic postconditioning was performed by 6 cycles of $10 \mathrm{~s}$ of reperfusion followed by $10 \mathrm{~s}$ of global ischemia immediately after the index ischemia. Drugs were infused from 5 min before reperfusion to the first $30 \mathrm{~min}$ of reperfusion (hatched rectangle). 
OR antagonist naloxone (M-Post + NAL), $5 \mu \mathrm{M}$ of the selective $\delta$-OR antagonist naltrindole (M-Post + NTD), and $100 \mathrm{nM}$ of the selective $\delta_{1}$-OR antagonist 7-benzylidenenaltrexone (M-Post + BNTX) were perfused along with morphine. The concentrations of morphine, naloxone, naltrindole and 7-benzylidenenaltrexone were chosen based on previous reports used in isolated working rat hearts $[10,11]$. An additional M-Post group was treated with 20,40 , or $60 \mu \mathrm{M}$ of a MPTP opener atractyloside (M-Post+ATR) to assess the involvement of MPTP in morphine-induced cardioprotection.

Morphine, naloxone, naltrindole, and 7-benzylidenenaltrexone were purchased from Tocris Cookson Inc., Ellisville, MO, USA. Atractyloside was purchased from Sigma-Aldrich Chemical., St. Louis, MO, USA. Chemicals were dissolved with distilled water and stored at $-20^{\circ} \mathrm{C}$ and were diluted with $\mathrm{KH}$ solution to the required final concentrations on the day of each experiment.

At the end of each experiment, ischemic (area at risk, AR) and infarcted (area of necrosis, AN) regions were measured with fluorescent polymer microspheres (Duke Scientific Corp., Palo Alto, CA, USA) and 2,3,5-triphenyltetrazolium chloride (SigmaAldrich Chemical., St. Louis, MO, USA) staining as described previously [12]. The AR and AN regions were quantified with the program ImageTool (UTHSCSA Image Tool, version 3.0). Infarct size was expressed as a percentage of the risk zone (AN/AR). All measurements were performed in a blinded fashion. Body weight (mean 301.6 $\pm 1.8 \mathrm{~g}$ ) and heart weight (mean $1.48 \pm 0.01 \mathrm{~g}$ ) were equivalent among the groups.

Data are presented as means \pm SEM. Data analysis was performed with a personal computer statistical software package (SPSS for Windows, Release 12.0; SPSS Inc, Chicago, IL, USA). Data were analyzed using one-way analysis of variance (ANOVA) with a Bonferroni post-hoc test. Differences were considered to be statistically significant when $P$ values were less than 0.05 .

\section{Results}

A total of 82 rat hearts were used for infarct size measurement. Five hearts were excluded for the following reasons: a CF $>18 \mathrm{ml} / \mathrm{min}(\mathrm{n}=1), \operatorname{LVDP}<80 \mathrm{mmHg}(\mathrm{n}=2)$, and sustained arrhythmia $(n=2)$ during stabilization. Therefore we report the data from 77 successfully completed infarct experiments.

Baseline CF, HR, LVDP, RPP, and $+\mathrm{dP} / \mathrm{dt}_{\max }$ averaged 12.3 $\mathrm{ml} / \mathrm{min}, 279.0$ beats/min, $133.6 \mathrm{mmHg}, 37.3 \mathrm{mmHg} / \mathrm{min} / 10^{3}$, and $3.5 \mathrm{mmHg} / \mathrm{s} / 10^{3}$, respectively. There were no significant differences in baseline cardiodynamic variables among the groups (Table 1). After $2 \mathrm{~h}$ of reperfusion, there were also no significant differences in CF, LVDP, RPP, and $+\mathrm{dP} / \mathrm{dt}_{\max }$ among

Table 1. Coronary Flow and Cardiodynamic Data

\begin{tabular}{|c|c|c|c|c|c|c|c|c|c|c|}
\hline \multirow{2}{*}{ coup } & \multicolumn{2}{|c|}{$\begin{array}{c}\mathrm{CF} \\
(\mathrm{ml} / \mathrm{min})\end{array}$} & \multicolumn{2}{|c|}{$\begin{array}{c}\mathrm{HR} \\
\text { (beats/min) }\end{array}$} & \multicolumn{2}{|c|}{$\begin{array}{c}\text { LVDP } \\
(\mathrm{mmHg})\end{array}$} & \multicolumn{2}{|c|}{$\begin{array}{c}\text { RPP } \\
\left(\mathrm{mmHg} \cdot \text { beats } / \mathrm{min} \cdot 10^{3}\right)\end{array}$} & \multicolumn{2}{|c|}{$\begin{array}{c}+\mathrm{dP} / \mathrm{dt}_{\max } \\
\left(\mathrm{mmHg} / \mathrm{s} / 10^{3}\right)\end{array}$} \\
\hline & e & $\mathrm{R}$ & eline & Rep & line & Repe & aseline & Repe & aseline & Reperfusio \\
\hline$N$ & 7 & $\begin{array}{r}5.8 \pm \\
(46.1 \pm\end{array}$ & 8 & $\begin{array}{c}267 \pm 8 \\
(95.1 \pm 2.4)\end{array}$ & $4 \pm 7$ & $\begin{array}{c}70 \pm 10 \\
(51.9 \pm 6.2)\end{array}$ & & $\begin{array}{c}19.1 \pm 3.0 \\
(49.7 \pm 6.4)\end{array}$ & .5 & $\begin{array}{r}1.6 \\
(45.2\end{array}$ \\
\hline Post & $11.9 \pm 0.5$ & $\begin{array}{c}6.3 \pm 0.5 \\
(53.7 \pm 5.4)\end{array}$ & $277 \pm 3$ & $\begin{array}{c}253 \pm 11 \\
(91.4 \pm 3.4)\end{array}$ & $139 \pm 7$ & $\begin{array}{c}82 \pm 7 \\
(59.1 \pm 4.6)\end{array}$ & $38.4 \pm 2.0$ & $\begin{aligned} 21.2 \pm \\
(55.1 \pm\end{aligned}$ & $3.4 \pm 0.3$ & $\begin{array}{r}1.6 \\
(49.1\end{array}$ \\
\hline M-Post & $12.2 \pm 0.7$ & $\begin{array}{r}5.3 \pm \\
(43.7 \pm\end{array}$ & $285 \pm 10$ & $\begin{array}{c}254 \pm 9 * \\
(89.2 \pm 2.1)\end{array}$ & $129 \pm 8$ & $\begin{array}{r}59 \\
(47.8\end{array}$ & $37.0 \pm$ & $\begin{array}{r}14.8 \\
(43.2\end{array}$ & $3.4 \pm 0.2$ & $\begin{array}{r}1 . \\
(49 .\end{array}$ \\
\hline I-Post + NAL & 11 & $\begin{array}{r}4.5 \\
(37.9\end{array}$ & 2 & $\begin{array}{c}266 \pm 11 \\
(89.2 \pm 2.1)\end{array}$ & 1 & $\begin{array}{r}59 \\
(44.5\end{array}$ & .5 & $\begin{array}{r}15.6 \\
(46.1\end{array}$ & .5 & $\begin{array}{r}1.4 \\
(45.4\end{array}$ \\
\hline M-Post + NTD & $12.0 \pm 0.9$ & $\begin{array}{r}3.7 \pm \\
(30.4 \pm\end{array}$ & $272 \pm 10$ & $\begin{array}{c}258 \pm 11 \\
(101.5 \pm 6.9)\end{array}$ & \pm 16 & $\begin{array}{c}61 \pm 6 \\
(46.4 \pm 3.6)\end{array}$ & 36.1 & & $3.4 \pm 0.7$ & $\begin{array}{r}1.7 \\
(54.3\end{array}$ \\
\hline M-Post + BNTX & $11.9 \pm 1.0$ & $\begin{array}{r}4.3 \pm \\
(35.2 \pm\end{array}$ & $272 \pm 17$ & $\begin{array}{c}244 \pm 15 \\
(96.0 \pm 6.9)\end{array}$ & $127 \pm 6$ & $\begin{array}{c}62 \pm 8 \\
(49.8 \pm 6.7)\end{array}$ & $34.0 \pm 1.4$ & $\begin{array}{r}15.0= \\
(44.5\end{array}$ & $3.3 \pm 0.2$ & $\begin{array}{c}1.6 \pm 0.1 \\
(50.9 \pm 5.3)\end{array}$ \\
\hline M-Post + ATR20 & 0.7 & $\begin{array}{c}6.0 \pm 1.1 \\
(46.9 \pm 6.5)\end{array}$ & $285 \pm 12$ & $\begin{array}{c}279 \pm 8 \\
(91.6 \pm 7.6)\end{array}$ & \pm 6 & $\begin{array}{c}60 \pm 6 \\
(47.2 \pm 6.4)\end{array}$ & $37.6=$ & $\begin{array}{c}16.8 \pm 1.9 \\
(47.4 \pm 7.9)\end{array}$ & \pm 0.2 & $\begin{array}{c}1.6 \pm 0.2 \\
(44.4 \pm 3.5)\end{array}$ \\
\hline M-Post + ATR40 & $12.9 \pm 0.8$ & $\begin{array}{c}6.5 \pm 1.6 \\
(48.0 \pm 8.3)\end{array}$ & $283 \pm 5$ & $\begin{array}{c}266 \pm 10 \\
(99.6 \pm 6.5)\end{array}$ & $136 \pm 4$ & $\begin{array}{c}63 \pm 4 \\
(47.0 \pm 4.4)\end{array}$ & $38.6 \pm 1.7$ & $\begin{array}{c}17.0 \pm 1.7 \\
(44.8 \pm 5.3)\end{array}$ & $3.7 \pm 0.2$ & $\begin{array}{c}1.8 \pm 0.1 \\
(51.7 \pm 5.1)\end{array}$ \\
\hline M-Post + ATR60 & $12.3 \pm 0.7$ & $\begin{array}{c}5.8 \pm 1.1 \\
(45.7 \pm 6.5)\end{array}$ & $280 \pm 15$ & $\begin{array}{c}239 \pm 10 \\
(86.7 \pm 4.9)\end{array}$ & $137 \pm 10$ & $\begin{array}{c}65 \pm 5 \\
(49.5 \pm 5.2)\end{array}$ & $38.2 \pm 3.4$ & $\begin{array}{c}15.4 \pm 1.2 \\
(42.9 \pm 5.1)\end{array}$ & $3.3 \pm 0.3$ & $\begin{array}{c}1.6 \pm 0.2 \\
(50.3 \pm 4.4)\end{array}$ \\
\hline ATR & $12.6 \pm 0.3$ & $\begin{array}{c}5.1 \pm 0.5 \\
(39.8 \pm 3.0)\end{array}$ & $286 \pm 9$ & $\begin{array}{c}267 \pm 6 \\
(93.6 \pm 2.9)\end{array}$ & $133 \pm 4$ & $\begin{array}{c}67 \pm 5 \\
(50.1 \pm 4.0)\end{array}$ & $38.1 \pm 0.9$ & $\begin{array}{c}17.9 \pm 1.6 \\
(47.0 \pm 3.7)\end{array}$ & $3.6 \pm 0.1$ & $\begin{array}{c}1.9 \pm 0.1 \\
(53.3 \pm 2.0)\end{array}$ \\
\hline
\end{tabular}

Values are means \pm SEM. CF: coronary flow, HR: heart rate, LVDP: left ventricular developed pressure, RPP: rate-pressure product, $+\mathrm{dP} / \mathrm{dt}_{\max }:$ velocity of left ventricular contraction, CON: control, I-Post: ischemic postconditioning, M-Post: morphine-induced postconditioning, NAL: $100 \mu \mathrm{M}$ of naloxone, NTD: $5 \mu \mathrm{M}$ of naltrindole, BNTX: $100 \mathrm{nM}$ of 7-benzylidenenaltrexone, ATR20, ATR40, and ATR60; atractyloside at 20, 40, and $60 \mu \mathrm{M}$, respectively. Numbers in parentheses are the percentage recovery after $2 \mathrm{~h}$ reperfusion compared to baseline levels. *Indicates $\mathrm{P}<$ 0.05 vs. baseline. There were no significant differences in variables among groups, except for HR. 


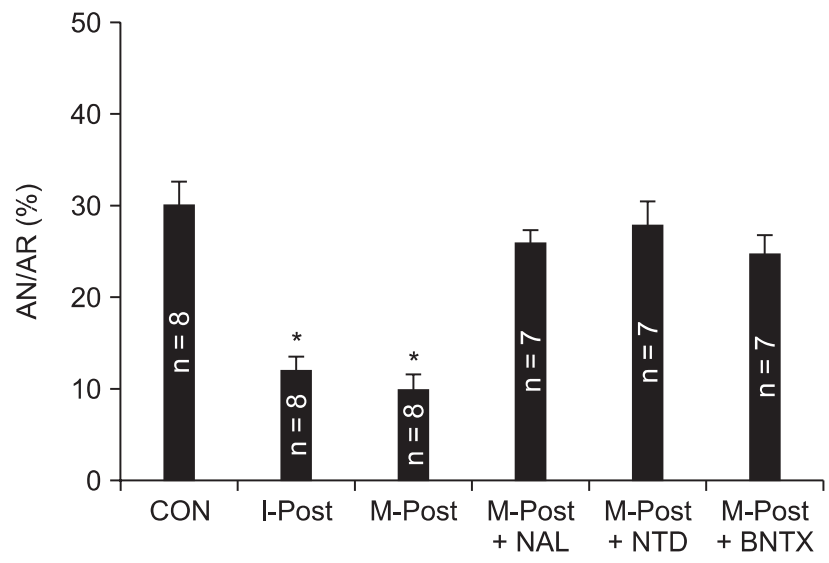

Fig. 2. Area of necrosis (AN) as percentage of area at risk (AR) as evaluated by triphenyltetrazolium chloride staining following $30 \mathrm{~min}$ regional ischemia and $2 \mathrm{~h}$ reperfusion in an isolated rat heart model. CON: control, I-Post: ischemic postconditioning, M-Post: morphineinduced postconditioning, NAL: $100 \mu \mathrm{M}$ of naloxone, NTD: $5 \mu \mathrm{M}$ of naltrindole, BNTX: $100 \mathrm{nM}$ of 7-benzylidenenaltrexone. Values are means \pm SEM. *Indicates $\mathrm{P}<0.05$ vs. CON.

the groups. In the M-Post group, however, HR was significantly decreased after $2 \mathrm{~h}$ of reperfusion compared to baseline levels ( $\mathrm{P}$ $<0.01)$.

As shown in Fig. 2, infarct size in control hearts was $30.0 \pm$ $3.7 \%$ of the $\mathrm{AR}$, and this result is in agreement with our recently reported infarct measurement study [12]. Treatment with 1 $\mu \mathrm{M}$ morphine significantly reduced myocardial infarction size $(9.8 \pm 2.5 \%, \mathrm{P}<0.001$ vs. CON $)$. This anti-infarct effect by morphine was similar with the infarct limitation effect by I-Post $(11.9 \pm 2.2 \%, \mathrm{P}>0.05$ vs. M-Post). Naloxone totally abrogated the infarct-limiting effect of morphine $(25.7 \pm 1.9 \%, \mathrm{P}<0.01$ vs. M-Post). In addition, the anti-infarct effect by morphine was also totally blocked by naltrindole $(27.8 \pm 4.3 \%$, $\mathrm{P}<0.05$ vs. M-Post) and 7-benzylidenenaltrexone (24.7 $\pm 3.7 \%, \mathrm{P}<0.01$ vs. M-Post). Naloxone, naltrindole and 7-benzylidenenaltrexone themselves had no effect on infarct size ( $\mathrm{P}>0.05 \mathrm{vs}$. CON).

We further tested the involvement of MPTP in the morphineinduced reduction of infarct during reperfusion by using incremental doses of the MPTP opener atractyloside. Concentrations of 20 and $40 \mu \mathrm{M}$ atractyloside could not attenuate the anti-infarct effect by morphine (Fig. 3). However, $60 \mu \mathrm{M}$ of atractyloside $(28.0 \pm 3.6 \%, \mathrm{P}<0.05$ vs. M-Post $)$ totally blocked the infarct-limiting effect by morphine at a dose that had no effect in non-treated hearts $(26.3 \pm 5.2 \%, \mathrm{P}<0.05$ vs. M-Post $)$.

\section{Discussion}

In the present study, morphine targeting reperfusion effectively reduced myocardial infarction in isolated rat hearts and this effect mimicked the anti-infarct effect of I-Post. The

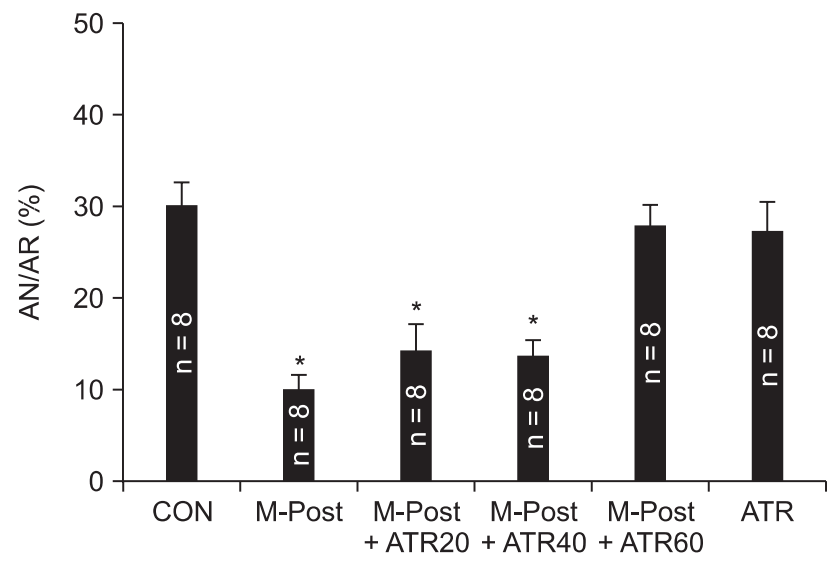

Fig. 3. Area of necrosis (AN) as percentage of area at risk (AR) as evaluated by triphenyltetrazolium chloride staining following $30 \mathrm{~min}$ regional ischemia and $2 \mathrm{~h}$ reperfusion in an isolated rat heart model. CON: control, M-Post: morphine-induced postconditioning, ATR20, ATR40, and ATR60: atractyloside 20, 40, and $60 \mu \mathrm{M}$, respectively. Values are means \pm SEM. *Indicates $\mathrm{P}<0.05$ vs. CON

infarct-reducing effect by morphine was totally inhibited by the $\delta$-OR antagonist naltrindole and the $\delta_{1}$-OR antagonist 7 -benzylidenenaltrexone, which suggests morphine activates the $\delta$-OR, especially $\delta_{1}$-OR. In addition, the infarct-limiting effect by morphine was also totally blocked by $60 \mu \mathrm{M}$ of the MPTP opener atractyloside, implying the involvement of MPTP in the morphine-induced anti-infarct effect. Taken together, our data strongly suggest that M-Post limits myocardial infarction via activation of $\delta_{1}$-OR and inhibition of MPTP opening in isolated rat hearts. After $2 \mathrm{~h}$ of reperfusion, there were no significant differences in cardiodynamic variables including LVDP, RPP and $+\mathrm{dP} / \mathrm{dt}_{\max }$ among the groups. However, HR was significantly decreased in the M-Post group. This may be caused by morphine's direct effect on the myocardium, causing a decrease in HR. Interestingly, the decrease in HR by M-Post group was reversed by OR antagonists and atractyloside.

Schultz et al. [1] first reported that the use of morphine to target ischemia mimicked the effect of I-Pre in open-chest rats. More recently, Gross and co-workers [4] demonstrated that the use of morphine to target reperfusion reduced the infarct size in I/R-injured rat hearts and this result is in agreement with our present study. In addition, the anti-infarct effect was as effective as I-Post in our study. Taken together, the data reinforce that morphine confers cardioprotection when administered not only during ischemia but also during reperfusion.

In adult ventricular cardiomyocytes, only $\delta$-OR and $\kappa$-OR subtypes were reported, although more recent data suggest that there are functional $\mu$-OR in rat cardiomyocytes [13]. It has been proposed that $\delta$-OR is responsible for the cardioprotective effect of I-Pre and M-Pre. In our previous report, cardioprotection 
by I-Post involved $\delta$-OR, especially $\delta_{1}$-OR in isolated rat hearts [10]. In addition, Gross et al. [14] recently reported that M-Post involves activation of $\delta$-OR in in vivo rat hearts. Therefore, we hypothesized the possibility of involvement of $\delta_{1}$-OR in M-Post. In the present study, the anti-infarct effect by M-Post was totally blocked by the nonspecific $\delta$-OR antagonist naltrindole and the $\delta_{1}$-OR antagonist 7-benzylidenenaltrexone. This result strongly suggests that M-Post activates $\delta$-OR, especially $\delta_{1}$-OR, even though we did not evaluate the involvement of $\kappa$-OR in this study.

Chen et al. [15] reported that M-Post confers cardioprotection via activation of $\kappa$-OR but not by $\delta$-OR. In their study, the $\kappa$-OR antagonist nor-binaltorphimine partly reversed the protective effects of M-Post, while naltrindole had no effect on M-Post. In their study, however, OR antagonists, such as naloxone, naltrindole, and nor-binaltorphimine, themselves also reduced infarct size. In addition, they induced M-Post at the onset of reperfusion while our M-Post was induced 5 min prior to reperfusion. Therefore, their results did not provide a clear distinction as to whether the infarct-limiting effect by M-Post was caused by M-Post itself or by OR antagonists. In the present study, however, our concentrations of naloxone, naltrindole and 7-benzylidenenaltrexone themselves had no effect on infarct size which suggests that the infarct-limiting effect by M-Post was caused entirely by M-Post itself.

Inhibition of MPTP is considered an end point target against myocardial I/R injury. MPTP remains closed under normal physiologic conditions but opens at the onset of reperfusion triggered by both $\mathrm{Ca}^{2+}$ overload and the excessive formation of reactive oxygen species [16]. The MPTP opening has been shown to result in both necrotic and apoptotic cell death. Inhibition of the MPTP opening in the setting of I/R injury is cardioprotective. Recently, Obame et al. [17] demonstrated that morphine-induced cardioprotection inhibited the MPTP opening by using the MPTP opener cyclosporine A as assessed by the calcein loading $\mathrm{Co}^{2+}$-quenching technique. More recently, $\mathrm{Xi}$ et al. [9] showed by confocal microscopy that morphine treatment prevented the MPTP opening in cardiomyocytes. We also previously reported that I-Post was mediated by inhibition of the MPTP opening via $\sigma$-opioid receptor activation [10]. The anti-infarct effect by M-Post was totally attenuated by an MPTP opener atractyloside in our isolated rat hearts, which suggests the involvement of MPTP in cardioprotection by M-Post. We used a $20 \mu \mathrm{M}$ concentration of atractyloside based on a previous report that the anti-infarct effect by bradykinin was blocked by this concentration of atractyloside [18]. However, $20 \mu \mathrm{M}$ and 40 $\mu \mathrm{M}$ of atractyloside could not block the infarct-limiting effect by M-Post in our present study. The infarct-reducing effect by M-Post could be blocked by $60 \mu \mathrm{M}$ of atractyloside and this concentration of atractyloside itself had no effect on infarct size.
Therefore, this result may suggest a stronger activity for M-Post to inhibit the MPTP opening than that for other cardioprotective strategies, and that higher concentrations of atractyloside may be required to block M-Post.

In conclusion, M-Post significantly reduced infarct size as compared to I-Post. The anti-infarct effect by M-Post involves $\delta$-OR, especially $\delta_{1}$-OR activation and MPTP inhibition. However, the involvement of other OR subtypes, such as $\delta_{2}$ $\mathrm{OR}$ and $\kappa-\mathrm{OR}$, and intermediate signaling pathways by M-Post should be determined in the future.

\section{References}

1. Schultz JE, Hsu AK, Gross GJ. Morphine mimics the cardioprotective effect of ischemic preconditioning via a glibenclamide-sensitive mechanism in the rat heart. Circ Res 1996; 78: 1100-4.

2. Schultz JJ, Hsu AK, Gross GJ. Ischemic preconditioning and morphine-induced cardioprotection involve the delta (delta) opioid receptor in the intact rat heart. J Mol Cell Cardiol 1997; 29: 2187-95.

3. Okubo S, Tanabe Y, Takeda K, Kitayama M, Kanemitsu S, Kukreja $\mathrm{RC}$, et al. Ischemic preconditioning and morphine attenuate myocardial apoptosis and infarction after ischemia-reperfusion in rabbits: role of delta-opioid receptor. Am J Physiol Heart Circ Physiol 2004; 287: H1786-91.

4. Gross ER, Hsu AK, Gross GJ. GSK3 beta inhibition and K(ATP) channel opening mediate acute opioid-induced cardioprotection at reperfusion. Basic Res Cardiol 2007; 102: 341-9.

5. Javadov S, Karmazyn M. Mitochondrial permeability transition pore opening as an endpoint initiate cell death and a putative target for cardioprotection. Cell Physiol Biochem 2007; 20: 1-22.

6. Halestrap AP, Clarke SJ, Javadov SA. Mitochondrial permeability transition pore opening during myocardial reperfusion-a target for cardioprotection. Cardiovasc Res 2004; 61: 372-85.

7. Javadov SA, Clarke S, Das M, Griffiths EJ, Lim KH, Halestrap AP. Ischaemic preconditioning inhibits opening of mitochondrial permeability transition pores in the reperfused rat heart. J Physiol 2003; 549: 513-24.

8. Gomez L, Paillard M, Thibault H, Derumeaux G, Ovize M. Inhibition of GSK3beta by postconditioning is required to prevent opening of the mitochondrial permeability transition pore during reperfusion. Circulation 2008; 117: 2761-8.

9. Xi J, Tian W, Zhang L, Jin Y, Xu Z. Morphine prevents the mitochondrial permeability transition pore opening through $\mathrm{NO} /$ cGMP/PKG $/ \mathrm{Zn}^{2+} / \mathrm{GSK}-3$ beta signal pathway in cardiomyocytes. Am J Physiol Heart Circ Physiol 2010; 298: H601-7.

10. Jang Y, Xi J, Wang H, Mueller RA, Norfleet EA, Xu Z. Postconditioning prevents reperfusion injury by activating delta-opioid receptors. Anesthesiology 2008; 108: 243-50.

11. Wang GY, Wu S, Pei JM, Yu XC, Wong TM. Kappa-but not deltaopioid receptors mediate effects of ischemic preconditioning on both infarct and arrhythmia in rats. Am J Physiol Heart Circ Physiol 2001; 280: H384-91.

12. Song DK, Jang Y, Kim JH, Chun KJ, Lee D, Xu Z. Polyphenol $(-)$-epigallocatechin gallate during ischemia limits infarct size via 
mitochondrial K(ATP) channel activation in isolated rat hearts. J Korean Med Sci 2010; 25: 380-6.

13. Zimlichman R, Gefel D, Eliahou H, Matas Z, Rosen B, Gass S, et al. Expression of opioid receptors during heart ontogeny in normotensive and hypertensive rats. Circulation 1996; 93: 1020-5.

14. Gross ER, Hsu AK, Gross GJ. Acute methadone treatment reduces myocardial infarct size via the delta-opioid receptor in rats during reperfusion. Anesth Analg 2009; 109: 1395-402.

15. Chen Z, Li T, Zhang B. Morphine postconditioning protects against reperfusion injury in the isolated rat hearts. J Surg Res 2008; 145: 287-94.

16. Piper HM, Meuter K, Schäfer C. Cellular mechanisms of ischemia- reperfusion injury. Ann Thorac Surg 2003; 75: S644-8.

17. Obame FN, Plin-Mercier C, Assaly R, Zini R, Dubois-Randé JL, Berdeaux A, et al. Cardioprotective effect of morphine and a blocker of glycogen synthase 3 beta, SB216763 [3-(2,4-dichlorophenyl)-4(1methyl-1H-indol-3-yl)-1H-pyrrole-2,5-dione], via inhibition of the mitochondrial permeability transition pore. J Pharmacol Exp Ther 2008; 326: 252-8.

18. Park SS, Zhao H, Mueller RA, Xu Z. Bradykinin prevents reperfusion injury by targeting mitochcondrial permeability transition pore through glycogen synthase kinase 3beta. J Moll Cel Cardiol 2006; 40: 708-16. 